\title{
BCL2-modifying factor promotes germ cell loss during murine oogenesis
}

\author{
Kavitha Vaithiyanathan 1 , Seng H Liew², Nadeen Zerafa², Thilini Gamage ${ }^{1}$, Michele Cook ${ }^{3}$, \\ Lorraine A O'Reilly ${ }^{3,4}$, Philippe Bouillet ${ }^{3,4}$, Clare L Scott ${ }^{3,4}$, Andreas Strasser ${ }^{3,4}$, Jock K Findlay ${ }^{1,5}$ \\ and Karla J Hutt ${ }^{2}$ \\ ${ }^{1}$ Hudson Institute of Medical Research, Clayton, Victoria, Australia, ${ }^{2}$ Development and Stem Cells Program, Monash \\ Biomedicine Discovery Institute and Department of Anatomy and Developmental Biology, Monash University, \\ Melbourne, Victoria, Australia, ${ }^{3}$ The Walter and Eliza Hall Institute of Medical Research, Parkville, Victoria, Australia, \\ ${ }^{4}$ Department of Medical Biology, University of Melbourne, Parkville, Victoria, Australia and ${ }^{5}$ Department of \\ Obstetrics and Gynaecology, Monash University, Clayton, Victoria, Australia
}

Correspondence should be addressed to KJ Hutt; Email: Karla.Hutt@monash.edu

\begin{abstract}
Apoptosis plays a prominent role during ovarian development by eliminating large numbers of germ cells from the female germ line. However, the precise mechanisms and regulatory proteins involved in germ cell death are yet to be determined. In this study, we characterised the role of the pro-apoptotic BH3-only protein, BCL2-modifying factor (BMF), in germ cell apoptosis in embryonic and neonatal mouse ovaries. BMF protein was immunohistochemically localised to germ cells at embryonic days 15.5 (E15.5) and E17.5 and postnatal day 1 (PN1), coincident with entry into the meiotic prophase, but was undetectable at E13.5, and only present at low levels at PN3 and PN5. Consistent with this expression pattern, loss of BMF in female mice was associated with a decrease in apoptosis at E15.5 and E17.5. Furthermore, increased numbers of germ cells were found in ovaries from Bmf ${ }^{-/-}$mice compared with WT animals at E15.5 and PN1. However, germ cell numbers were comparable between $\mathrm{Bmf}^{-/-}$and WT ovaries at PN3, PN5 and PN10. Collectively, these data indicate that BMF mediates foetal oocyte loss and its action limits the maximal number of germ cells attained in the developing ovary, but does not influence the number of primordial follicles initially established in ovarian reserve. Reproduction (2016) 151 553-562
\end{abstract}

\section{Introduction}

Gamete formation begins early in embryonic development ( E7.5) in mice with the specification of a small number of primordial germ cells in the proximal epiblast (Ginsburg et al. 1990, Lawson \& Hage 1994, Saitou et al. 2002, Hayashi et al. 2007). Once specified, these cells begin to proliferate and migrate into the gonad, where they lose mobility (Richardson \& Lehmann 2010). Within the developing embryonic ovary, primordial germ cells become oogonia and continue to proliferate, forming cysts or nest-like structures of interconnected germ cells (Mork et al. 2012, Lei \& Spradling 2013). Eventually the oogonia transition from mitosis to meiosis (beginning between E13.5 and E15.5 in mice) and become primary oocytes (Miles et al. 2010). Around the time of birth in mice, the nests begin to break down, and pre-granulosa cells surround individual diplotenearrested oocytes, forming the initial pool of primordial follicles (Lei \& Spradling 2013). A striking characteristic of normal ovarian development and establishment of the initial pool of primordial follicles, which constitute the ovarian reserve, leads to the death of large numbers of primordial germ cells, oogonia and oocytes (Baker 1963). The reasons underlying the developmentally regulated death of germ cells during oogenesis and the specific mechanisms by which this occurs have not been fully characterised.

Several studies suggest that germ cell death is mediated by the intrinsic (also known as the 'mitochondrial', 'BCL2-regulated' or 'stress-induced') apoptosis pathway (Ratts et al. 1995, Felici et al. 1999, Rucker et al. 2000, Greenfeld et al. 2007a, Ene et al. 2013, Myers et al. 2014). The intrinsic apoptosis pathway is regulated by the relative levels and activities of pro- and anti-apoptotic members of the BCL2 protein family (Youle \& Strasser 2008, Czabotar et al. 2014). The BCL2 family can be subdivided into three groups: i) the anti-apoptotic members, including BCL2, BCL-XL (BCL2L1), MCL1, $A 1$ (BFL1) and BCL-w (BCL2L2), which are required for cell survival; ii) the multi-BCL2 homology $3(\mathrm{BH} 3)$ domain pro-apoptotic family members BAX, BAK and possibly also BOK, whose activation leads to mitochondrial outer membrane permeabilisation and consequent 
destruction of the cell and iii) the pro-apoptotic $\mathrm{BH} 3-$ only proteins, including BIM (BCL2L11), PUMA (BBC3), $\mathrm{BID}, \mathrm{BAD}, \mathrm{BCL} 2$-modifying factor (BMF), BIK, HRK and NOXA (PMAIP1) (Happo et al. 2012, Moldoveanu et al. 2014). The BH3-only proteins initiate apoptosis by binding and neutralising pro-survival BCL2 family members (by stabilisation or degradation), which relieves the inhibition of BAX and BAK (Happo et al. 2012). Certain BH3only proteins, including BIM, PUMA and BMF, may also directly interact with and activate BAX/BAK. Activation of BAX/BAK leads to the release of cytochrome $C$ and other apoptogenic factors from the mitochondria, following which the apoptosome is formed. The activation of caspase-9 and the effector caspases (e.g. caspase-3 and -7) causes cell demolition (Strasser et al. 2000).

In mice, germ cell survival has been previously shown to require the anti-apoptotic protein $\mathrm{BCL}-\mathrm{XL}$ between $\mathrm{E} 12.5$ and E15.5, and a reduction in its function results in decreased primordial follicle numbers in neonatal ovaries (Rucker et al. 2000). Moreover, mice deficient in the anti-apoptotic protein BCL2 are born with reduced primordial follicle numbers (Ratts et al. 1995), whereas overexpression of BCL2 promotes germ cell survival and increases the size of the primordial follicle pool in neonates (Flaws et al. 2001, Flaws et al. 2006). We have recently shown that PUMA mediates germ cell death in mice before E13.5 (during the migratory and/or proliferative phase) and loss of PUMA results in approximately two-fold increase in primordial follicle number at birth (Myers et al. 2014). Additionally, there has been much attention focussed on the role of the pro-apoptotic protein BAX in germ cell death (Rucker et al. 2000, Stallock et al. 2003, Alton \& Taketo 2007, Greenfeld et al. 2007a,b, Perez et al. 2007, Ke et al. 2013). Even though many of these studies have produced conflicting results regarding the requirement for $\mathrm{BAX}$ in the elimination of germ cells during different stages of ovarian development, there is consensus within the field that BAX is an important regulator of female germ cell death.

$\mathrm{BMF}$, similar to PUMA, is a pro-apoptotic BH3-only protein that binds pro-survival proteins BCL2, BCL-XL and BCL-W to initiate apoptosis (Thomadaki \& Scorilas 2006). BMF can be activated by u.v. radiation, glucocorticoids, tyrosine kinase inhibitors and HDAC inhibitors (Happo et al. 2012), and studies on granulocytes suggest that BMF may be a critical initiator of apoptosis following cytokine withdrawal (Villunger et al. 2003). In the testes, BMF may be important for mediating the death of germ cells when they lose Sertoli cell attachment and may thus act as a quality control mechanism (O'Donnell et al. 1996). It is proposed that separation of germ cells from the Sertoli cells activates JNK1, which leads to the phosphorylation of BMF and its relocation from the sub-acrosomal space to the cytoplasm of round spermatids, thereby triggering their apoptosis (Stratton et al. 1973, O'Donnell et al. 1996, Show et al. 2004, Show et al. 2008). We have previously shown that BMF plays an important role in primordial follicle loss in mice between the ages of postnatal day (PN20) and PN100 and that adult mice deficient in BMF $\left(\mathrm{Bmf}^{--}\right)$contain approximately two times the number of primordial follicles as WT mice and therefore have prolonged fertility (Liew et al. 2014). However, the role of BMF in regulating germ cell death during oogenesis has not been examined before. In this study, we utilised gene-targeted mice to investigate the role of BMF in mediating germ cell death during ovarian development.

\section{Materials and methods}

\section{Mice}

WT and $\mathrm{Bmf}^{-1-}$ mice on a C57BL/6 background (Labi et al. 2008) were housed in a temperature-controlled pathogenfree facility, with a $12 \mathrm{~h}$ light:12 h darkness cycle, and with free access to mouse chow and water. Mice for breeding were between the ages of 7 weeks and 6 months. To collect embryos, timed matings were set up and the morning of a vaginal plug was designated as E0.5. All experiments with animals were approved by the Animal Ethics Committee at Monash University (MMCB/2013/07) and carried out in accordance with the Australian Code of Practice for the Care and Use of Animals for Scientific Purposes. One ovary from each mouse was fixed for stereological examination, whereas the contralateral ovary was fixed for immunofluorescence, immunohistochemistry and TUNEL analyses.

\section{Stereological examination}

Ovaries from WT and $B \mathrm{mf}^{-/-}$mice were harvested at E13.5, E15.5, E17.5, PN1, PN3, PN5 and PN10 ( $n=3-7 /$ genotype per age) and fixed in Bouin's solution. Fixed tissues were processed into hydroxyethyl methacrylate resin (Technovit 7100; Kulzer \& Co., Friedrichsdorf, Germany), serially sectioned at $20 \mu \mathrm{m}$ with a Leica RM2165 Microtome (Leica Microsystems Nussloch $\mathrm{GmbH}$, Nussloch, Germany) and stained with periodic acid-Schiff and haematoxylin. Germ cells (including oocytes in follicles) were counted in every third section using the optical dissector/fractionator technique as described (Myers et al. 2004, Kerr et al. 2006, Liew et al. 2014). Germ cell counting was performed using a $100 \times$ oil immersion objective mounted on an Olympus BX50 microscope with an Autoscan stage (Autoscan Systems Pty Ltd, Melbourne, VIC, Australia) controlled by CASTGRID Stereological Software (CAST 2002; Olympus).

\section{TUNEL analysis}

Ovaries from WT and $\mathrm{Bmf}^{-/-}$mice were fixed in $4 \%$ paraformaldehyde or formalin, de-hydrated, embedded in paraffin, serially sectioned at $5 \mu \mathrm{m}$ and mounted on superfrost glass slides. Apoptotic cells were detected using the ApopTag Peroxidase In Situ Apoptosis Detection Kit (Millipore) according to the manufacturer's instructions. Sections were counterstained with haematoxylin. To quantify apoptotic cell numbers, three to five sections per ovary (middle cross section, and one or two 

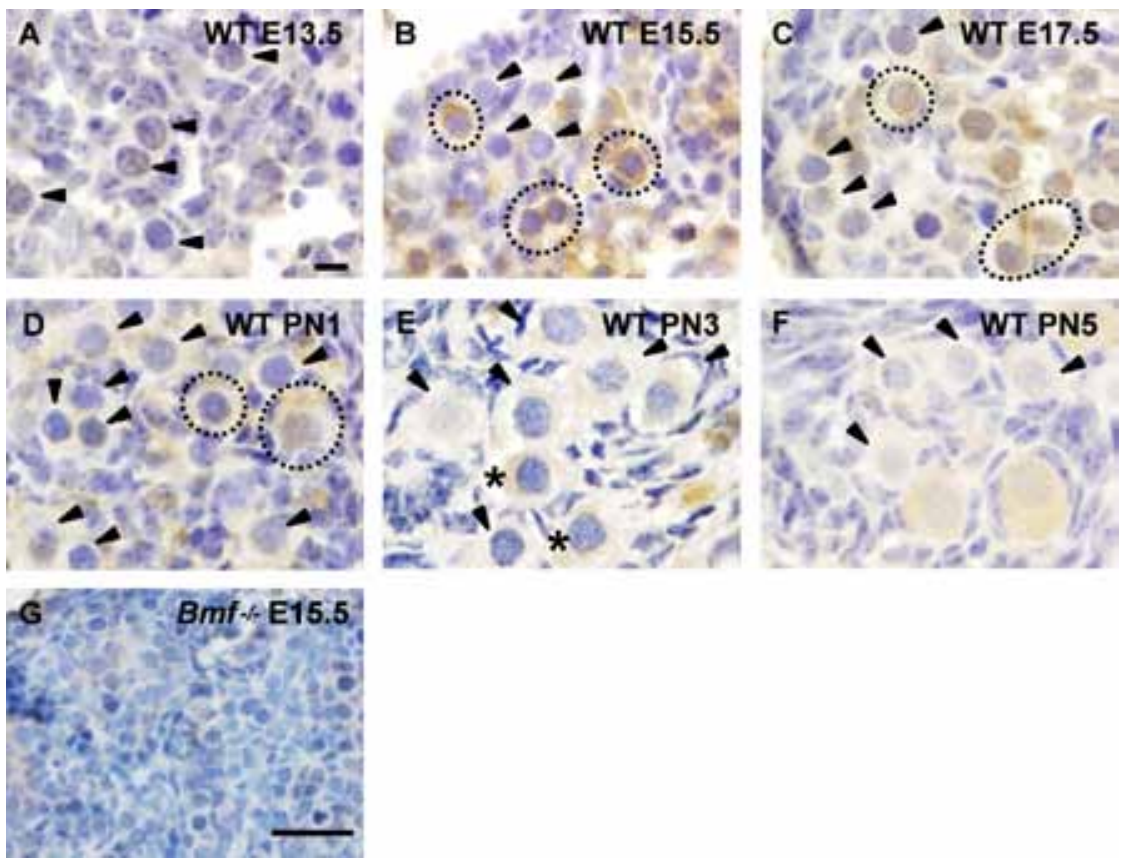

Figure $1 \mathrm{BMF}$ expression in mouse ovaries. Representative immunohistochemical staining for BMF in WT mouse ovaries from E13.5 to PN5 (A, B, C, D, E and F). Dotted lines surround germ cells with BMF immunoreactivity, seen as brown staining. Arrowheads indicate germ cells without BMF immunoreactivity. Asterisks indicate very weak immunoreactivity. A representative ovarian section from an E15.5 Bmf ${ }^{-1-}$ mouse (negative control) in which no staining with this antibody against BMF was observed (G). Scale bar (A, B, C, D, E and F), $10 \mu \mathrm{m}$ and (G) $50 \mu \mathrm{m}$.

sections on either side with a minimum of $20 \mu \mathrm{m}$ interval) from three to five animals per genotype were analysed. TUNELpositive cells (mean \pm S.E.M.) were expressed per $10^{4} \mu \mathrm{m}^{2}$ ovarian tissue area as described previously (Kerr et al. 2012, Myers et al. 2014).

\section{Immunofluorescence and immunohistochemical staining}

Ovaries ( $n=3-5$ ovaries/genotype per age) were fixed in formalin or $4 \%$ paraformaldehyde, processed into paraffin and $5 \mu \mathrm{m}$ sections were cut and mounted on slides. Following de-waxing and re-hydration, slides were microwaved for 10 min in $0.01 \mathrm{M}$ sodium citrate buffer ( $\mathrm{pH}$ 6) to unmask antigens. Endogenous peroxidases were inhibited by incubating slides for $30 \mathrm{~min}$ in $0.3 \% \mathrm{H}_{2} \mathrm{O}_{2}$ followed by $1 \mathrm{~h}$ with $10 \%$ normal goat serum to block non-specific binding of antibodies. Sections were then incubated with primary antibody to BMF

Table 1 Number of TUNEL-positive cells in WT and $\mathrm{Bmf}^{-{ }^{-}}$ovaries.

\begin{tabular}{lcc}
\hline & \multicolumn{2}{c}{ Number of TUNEL-positive cells $\mathbf{( 1 0}^{\mathbf{4}} \mathbf{\mu m}^{\mathbf{2}} \mathbf{)}$} \\
\cline { 2 - 3 } Age & WT & $B m f^{-/-}$ \\
\hline E13.5 & $0.379 \pm 0.096^{*, \neq}$ & $0.201 \pm 0.015^{*}$ \\
E15.5 & $1.103 \pm 0.123^{+}$ & $0.452 \pm 0.096^{*, \|}$ \\
E17.5 & $0.576 \pm 0.089^{\ddagger}$ & $0.300 \pm 0.030^{*, \S}$ \\
PN1 & $0.015 \pm 0.015^{*}$ & $0.034 \pm 0.017^{*}$ \\
PN3 & $0.015 \pm 0.015^{*}$ & $0 \pm 0^{*}$ \\
PN5 & $0.033 \pm 0.017^{*}$ & $0 \pm 0^{*}$ \\
\hline
\end{tabular}

Data represent mean \pm S.E.M. Within a column, means with different symbols in superscript indicate statistical significance $(P<0.05)$, whereas means sharing a symbol in their superscript are not significantly different ${ }^{\S} P<0.05$ and $\| P<0.005$ for comparison of $B \mathrm{mf}^{-/-}$vs WT at each age.
(17A9, 1:200; ENZO Life Sciences, Farmingdale, NY, USA; Labi et al. 2008), which we have previously validated for use in immunohistochemistry (Liew et al. 2014), for $1 \mathrm{~h}$ at $37^{\circ} \mathrm{C}$ or overnight at $4{ }^{\circ} \mathrm{C}$, followed by biotinylated goat anti-rat IgG secondary antibody (1:400; Zymed, San Francisco, CA, USA) for $1 \mathrm{~h}$ at room temperature. Slides were incubated for further 30 min with the avidin-biotin peroxidase complex (Vector Laboratories, Burlingame, CA, USA) and peroxidase activity was visualised using 3,3'-diaminobenzidine as the substrate. Sections were counterstained with haematoxylin. For negative controls, staining was performed with IgG isotype-matched antibodies, or with the primary antibody omitted. Additionally, ovarian sections from $B \mathrm{mf}^{-/-}$mice were used as negative control samples.

Immunofluorescent staining was performed using antibodies against DDX4 (MVH, 1:800; Abcam), H2AFX ( $\gamma \mathrm{H} 2 \mathrm{AX}, 1: 500$; Abcam), phosphohistone 3 (Ser28, PH3, 1:200; Upstate) and TAp63 (1:100, gift from Dr F McKeon (Suh et al. 2006)). For negative controls, staining was performed with IgG isotypematched antibodies, or with the primary antibody omitted. Antigen retrieval and blocking were performed as described above. Sections were incubated with primary antibodies overnight at $4^{\circ} \mathrm{C}$ and secondary antibodies (Alexa488 or 568-conjugated goat antibodies to rabbit or mouse IgG, 1:400, Molecular Probes) for $1 \mathrm{~h}$ at room temperature. Sections were counterstained with TOPR03 (Molecular Probes) and slides were mounted with FluorSave (Millipore). Slides were analysed by fluorescent confocal microscopy using an Olympus IX81 microscope.

To estimate the proportion of mitotic germ cells at E13.5, the number of germ cells positive for both $\mathrm{PH} 3$ (mitotic marker) and $\mathrm{MVH}$ (germ cell marker) was divided by the total number 
Table 2 Number of germ cells in WT and $B m f^{-/-}$ovaries.

\begin{tabular}{lccccc}
\hline & \multicolumn{2}{c}{ WT } & & \multicolumn{3}{c}{$\mathbf{B m f}^{-/-}$} \\
\cline { 2 - 3 } \cline { 5 - 6 } Age & $\begin{array}{c}\text { Number } \\
\text { of } \\
\text { ovaries }\end{array}$ & $\begin{array}{c}\text { Number of } \\
\text { germ cells }\end{array}$ & & $\begin{array}{c}\text { Number } \\
\text { of } \\
\text { ovaries }\end{array}$ & $\begin{array}{c}\text { Number of } \\
\text { germ cells }\end{array}$ \\
\hline E13.5 & 4 & $3572 \pm 847^{*}$ & & 3 & $2917 \pm 922^{*}$ \\
E15.5 & 5 & $16,448 \pm 735^{+}$ & & 6 & $22,443 \pm 2161^{+}$ \\
E17.5 & 6 & $15,643 \pm 2444^{+}$ & & 5 & $15,889 \pm 3238^{+, \neq}$ \\
PN1 & 6 & $10,377 \pm 2033^{+, \neq}$ & & 6 & $15,988 \pm 1019^{+, \neq, \S}$ \\
PN3 & 6 & $7188 \pm 1337^{*, \neq}$ & & 6 & $11,560 \pm 1691^{*, \neq, \S}$ \\
PN5 & 6 & $7185 \pm 901^{*, \neq}$ & & 7 & $9745 \pm 827^{*, \S}$ \\
PN10 & 7 & $7267 \pm 610^{*, \neq}$ & & 6 & $7940 \pm 1396^{*}$ \\
\hline
\end{tabular}

Data represent mean \pm S.E.M. Within a column, means with different symbols in superscript indicate statistical significance $(P<0.05)$, whereas means sharing a symbol in their superscript are not significantly different.

of $\mathrm{MVH}$-positive germ cells in three to five sections per ovary, $n=3-5$ animals/age per genotype. For this analysis, a middle cross section and at least one section on either side were used. The timing of meiotic progress $(\gamma \mathrm{H} 2 \mathrm{AX})$ and meiotic arrest (TAp63) were similarly analysed.

\section{Statistical analyses}

Statistical analyses were performed using GraphPad Prism 6 Software (GraphPad Software, Inc.). Data presented as means \pm S.E.M. were analysed by $t$-test or ANOVA followed by Holm-Sidak's multiple comparison test when more than two groups were compared. Proportions of cells in a population were analysed using the two-sample $t$-test between precents method. Differences were considered statistically significant when $P<0.05$.

\section{Results}

\section{BMF is expressed by female germ cells during ovarian development}

BMF protein expression was analysed by immunohistochemistry in ovaries from embryonic and early postnatal WT mice (Fig. 1A, B, C, D, E and F). BMF was not detected in ovarian tissue at E13.5 (Fig. 1A). At E15.5, BMF protein expression was localised to the

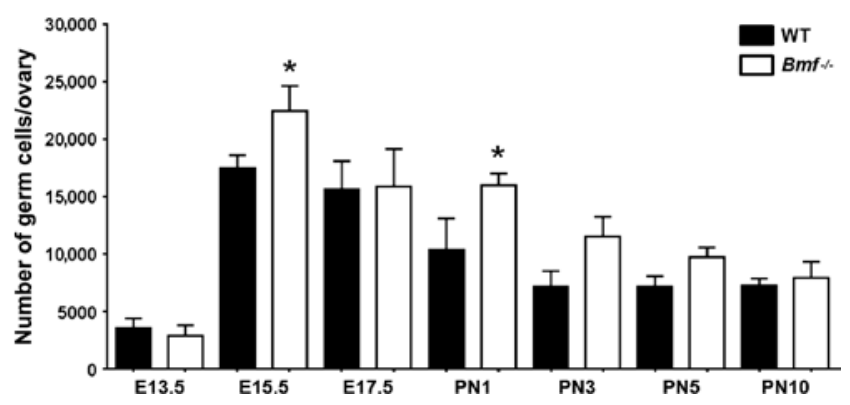

Figure 2 Germ cell numbers in ovaries from WT and $B m f^{-/-}$mice. Germ cells were counted in ovaries from E13.5 to PN10. Data are presented as mean \pm S.E.M. ${ }^{*} P<0.05$ for comparison of $B m f^{-1-}$ vs WT mice at each age. cytoplasm of many germ cells $(\sim 80 \%$ of germ cells had detectable levels of BMF; Fig. 1B). Some somatic cells within the ovary at E15.5 also appeared to be stained for BMF. BMF was also detected in $50 \%$ germ cells at E17.5 and PN1, but was only weakly expressed or absent from primordial follicles at PN3 or PN5 (Fig. 1C, D, E and F). No immunostaining was observed when ovarian tissue sections from $B \mathrm{mf}^{-/-}$mice were used (Fig. 1G), confirming the specificity of the antibody.

\section{Loss of BMF is associated with decreased apoptosis within ovaries}

Apoptosis was analysed in embryonic and early postnatal ovaries from WT and $\mathrm{Bmf}^{-{ }^{--}}$mice using the TUNEL assay (Table 1). In ovaries from WT females, there was a significant increase in the numbers of TUNELpositive cells between E13.5 and E15.5. The numbers of TUNEL-positive cells fell between E15.5 and E17.5, and then again between E17.5 and PN1 (Table 1). Very few TUNEL-positive cells were present in ovaries from WT females at PN1, PN3 and PN5 and there was no difference observed between these ages (Table 1). In ovaries
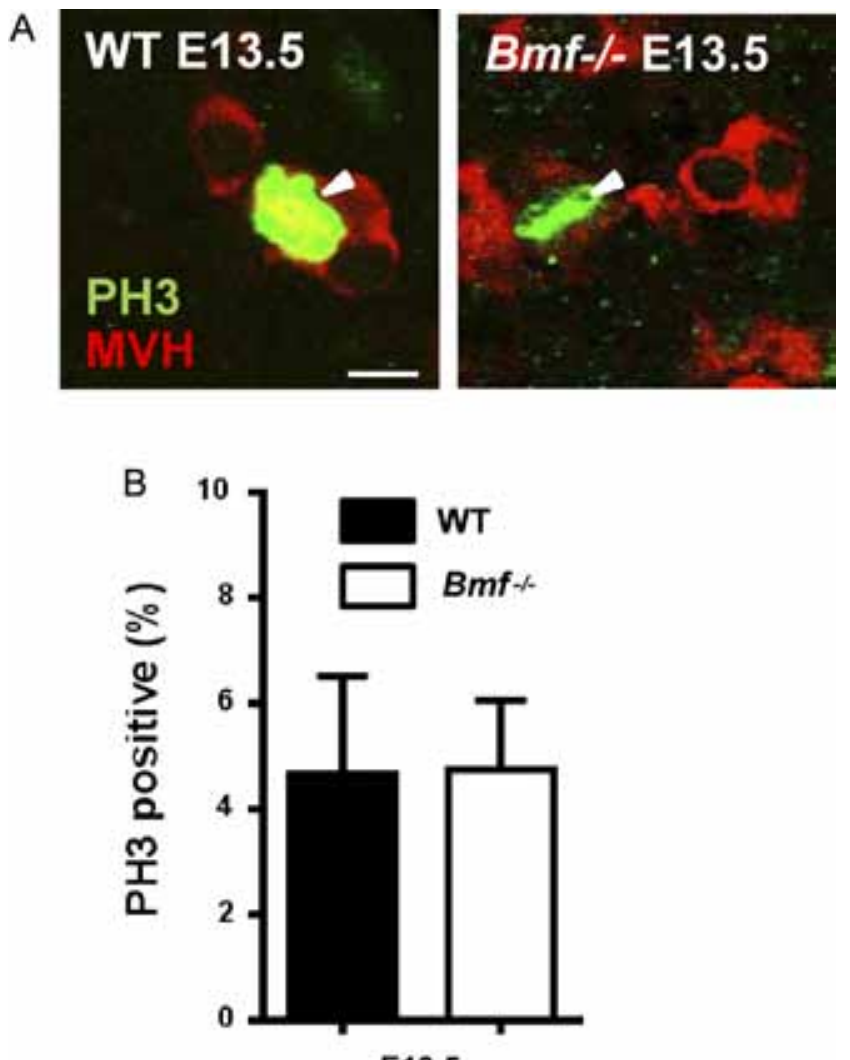

E13.5

Figure 3 The proportions of mitotic germ cells in the ovaries of WT and $\mathrm{Bmf}^{-1-}$ mice. (A) Proliferation was monitored in WT and $\mathrm{Bmf}^{-1-}$ ovaries at E13.5 using staining for the mitotic marker $\mathrm{PH} 3$ (red) and the germ cell marker MVH (green). Arrowheads indicate mitotic germ cells. Scale bar, $10 \mu \mathrm{m}$. (B) The proportions of $\mathrm{MVH}$-positive germ cells that were also $\mathrm{PH} 3$ positive are indicated. 
A
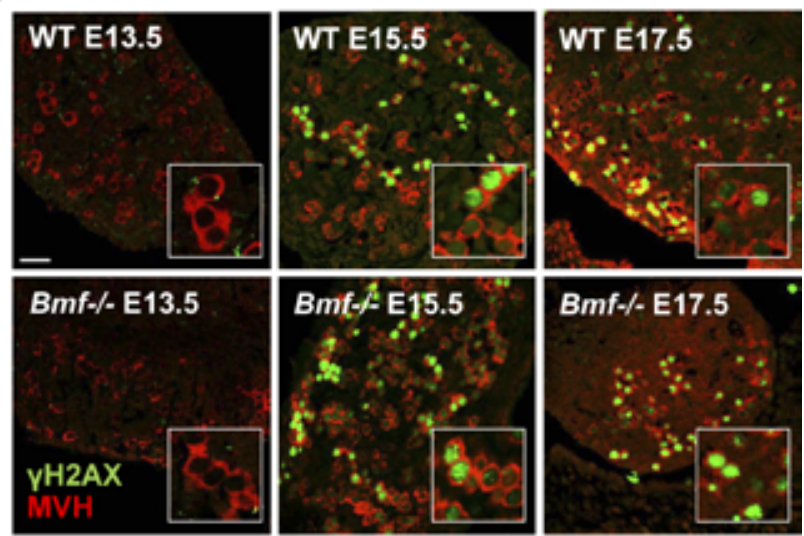

B

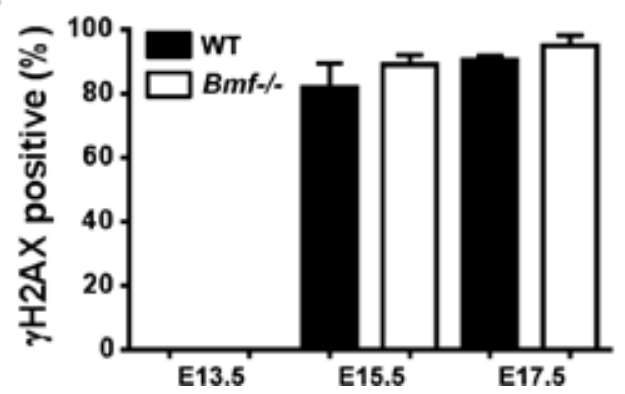

Figure 4 Timing of the mitotic to meiotic transition in germ cells of WT and $B m f^{-1-}$ mice. (A) The timing of the mitotic to meiotic transition was assessed in WT and $\mathrm{Bmf}^{-1-}$ ovaries from E13.5 to PN3 using staining for the meiotic marker $\gamma \mathrm{H} 2 \mathrm{AX}$ (green) and the germ cell marker MVH (green). Scale bar, $25 \mu \mathrm{m}$. (B) The proportions of $\mathrm{MVH}$-positive germ cells that were also $\gamma \mathrm{H} 2 \mathrm{AX}$ positive are indicated.

from $B m f^{--}$females, the numbers of TUNEL-positive cells did not change significantly with age, although there was a trend towards greater numbers of apoptotic cells at E15.5 and E17.5 compared with E13.5, PN1, PN3 and PN5 (Table 1). When ovaries from WT and $\mathrm{Bmf}^{-/-}$mice of the same age were compared, significantly fewer TUNEL-positive cells were detected in ovaries from Bmf ${ }^{--}$mice at E15.5 and E17.5 (Table 1). Although there also appeared to be decreased numbers of apoptotic cells at E13.5 in Bmf $\mathrm{Br}^{-1}$ ovaries compared with ovaries from WT mice, this difference was not statistically significant (Table 1 ). There were also no significant differences in the numbers of TUNEL-positive cells between ovaries from WT and $B \mathrm{mf}^{-1-}$ mice at PN1, PN3 and PN5 (Table 1).

\section{Loss of BMF results in increased germ cell number in embryonic and early postnatal ovaries}

Germ cells (including oocytes in follicles) were counted in WT and $B \mathrm{Ff}^{--}$ovaries during embryonic and early postnatal development (Table 2 and Fig. 2). In ovaries from WT females, germ cell numbers increased between E13.5 and E15.5, were similar at E15.5 and E17.5 and then declined after this point (Table 2). When ovaries from WT and $\mathrm{Bmf}^{-/-}$mice of the same age were compared, the number of germ cells per ovary was similar at E13.5 (Fig. 2). Significantly increased numbers of germ cells were observed in ovaries from $\mathrm{Bmf}^{-/}$compared with WT mice at E15.5, but then germ cell numbers in the $\mathrm{Bmf}^{-{ }^{--}}$mice returned to WT levels at E17.5 (Fig. 2). Increased numbers of germ cells were observed in ovaries from $\mathrm{Bmf}^{-1-}$ mice when compared with WT mice at PN1. Although there was a trend towards increased germ cell numbers in ovaries from $\mathrm{Bmf}^{-1-}$ compared with WT mice at PN3 and PN5, this difference was not significant (Fig. 2). At PN10, which corresponds to the time when the initial pool of primordial follicles is fully established in the mouse ovary, the numbers of germ cells in ovaries from WT and Bmf ${ }^{-1-}$ mice were similar (Fig. 2).

\section{The proportion of mitotic germ cells is similar in ovaries from WT and $\mathrm{Bmf}^{\prime-}$ mice}

To explore the possibility that the increase in germ cell numbers observed at E15.5 in $\mathrm{Bmf}^{-1-}$ mice might be due to increased proliferation, ovaries from E13.5 mice were co-stained with the mitotic marker $\mathrm{PH} 3$ and germ cell marker $\mathrm{MVH}$ and the proportions of proliferative germ
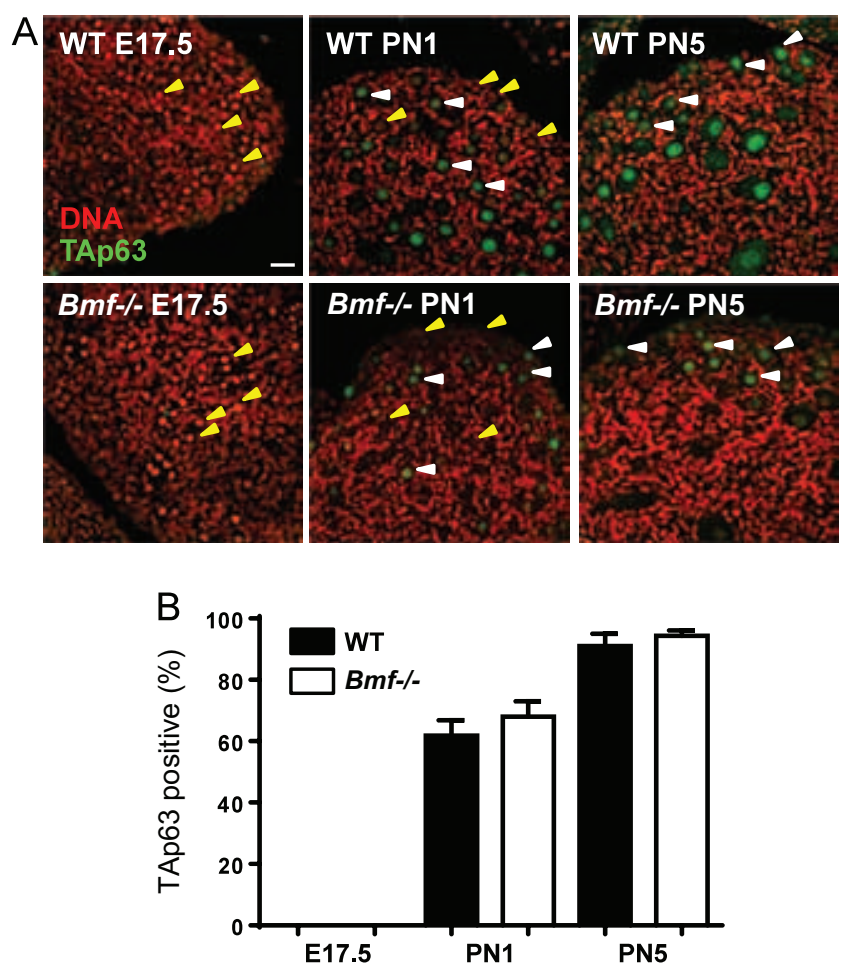

Figure 5 Entry into meiotic arrest of germ cells in ovaries of WT and $B \mathrm{mf}^{-1-}$ mice. The timing of the meiotic arrest was assessed in WT and Puma $^{-1-}$ ovaries at E17.5, PN1 and PN5 using staining for the diplotene marker TAp63 (green). DNA was counterstained with TOPRO3 (red). Yellow arrows indicate oocytes lacking TAp63 staining. White arrows indicate oocytes positively stained for TAp63. Scale bar, $25 \mu \mathrm{m}$. (B) The proportions of germ cells that were also TAp63 positive are indicated. 
cells were determined. No difference in the percentages of MVH-positive germ cells simultaneously labelled with $\mathrm{PH} 3$ was observed between $\mathrm{Bmf}^{-/}$and WT ovaries at E13.5, a time of active germ cell proliferation (Fig. 3). At E15.5, PH3-positive germ cells could no longer be detected in WT or Bmf $f^{-1-}$ ovaries, indicating that proliferation had ceased and meiosis had begun (not shown).

\section{Timing of the mitotic to meiotic transition is unchanged in ovaries from $\mathrm{Bmf}^{-/}$mice}

Expression of the meiotic prophase marker $\gamma \mathrm{H} 2 \mathrm{AX}$ (first expressed at leptotene; Hunter et al. 2001) was used to monitor the timing of meiotic entry in ovaries from WT and $\mathrm{Bmf}^{-/-}$mice. $\gamma \mathrm{H} 2 \mathrm{AX}$ staining was almost completely undetectable at E13.5, with only one to two $\gamma \mathrm{H} 2 \mathrm{AX}$-positive oocytes identified in all of the sections analysed (Fig. 4). By E15.5, most oocytes were labelled with $\gamma \mathrm{H} 2 \mathrm{AX}$, with no differences observed between ovaries from WT and $\mathrm{Bmf}^{-/-}$mice (Fig. 4). These observations suggest that meiotic entry, and thus cessation of mitosis, occur at a similar time in female germ cells in WT and $B m f^{-/}$mice.

\section{Entry into meiotic arrest is not affected by loss of BMF}

TAp63, which is expressed by oocytes as they enter diplotene (Suh et al. 2006), was used as a marker of meiotic arrest. TAp63 was not detected in ovaries from WT and $\mathrm{Bmf}^{-/-}$mice at E17.5 (Fig. 5). At PN1, 65\% of oocytes in ovaries from WT and $\mathrm{Bmf}^{-/}$mice expressed TAp63, consistent with similar rates of meiotic progression in WT and $B m f^{-1-}$ ovaries (Fig. 5). Nearly all $B m f^{-/-}$and WT oocytes expressed TAp63 at PN5 (Fig. 5).

\section{BMF is not required for nest breakdown or primordial follicle assembly}

Apoptosis is proposed to play an essential role in the breakdown of germ cell nests into individual oocytes, which can then be assembled into primordial follicles (Pepling \& Spradling 2001). To determine whether BMF-mediated apoptosis is important for germ cell nest breakdown, $20 \mu \mathrm{M}$ thick ovarian sections from PN1, PN3 and PN5 WT and $\mathrm{Bmf}^{-1-}$ mice stained with periodic acid-Schiff and haematoxylin were analysed and nest breakdown and follicle assembly monitored (Fig. 6A and B). Germ cell nests were easily observed in ovaries from WT and $\mathrm{Bmf}^{-1-}$ mice at PN1 as clusters of oocytes (Fig. 6A). No morphological differences in nest structure were observed between ovaries from WT and $B m f^{-1-}$ at this time (Fig. 6). Individual oocytes and primordial follicles were also observed at PN1 and there were no differences in the proportions of oocytes in nests vs follicles between ovaries from WT and $\mathrm{Bmf}^{-/-}$mice (10 and $18 \%$ of total germ cells were follicles in WT and
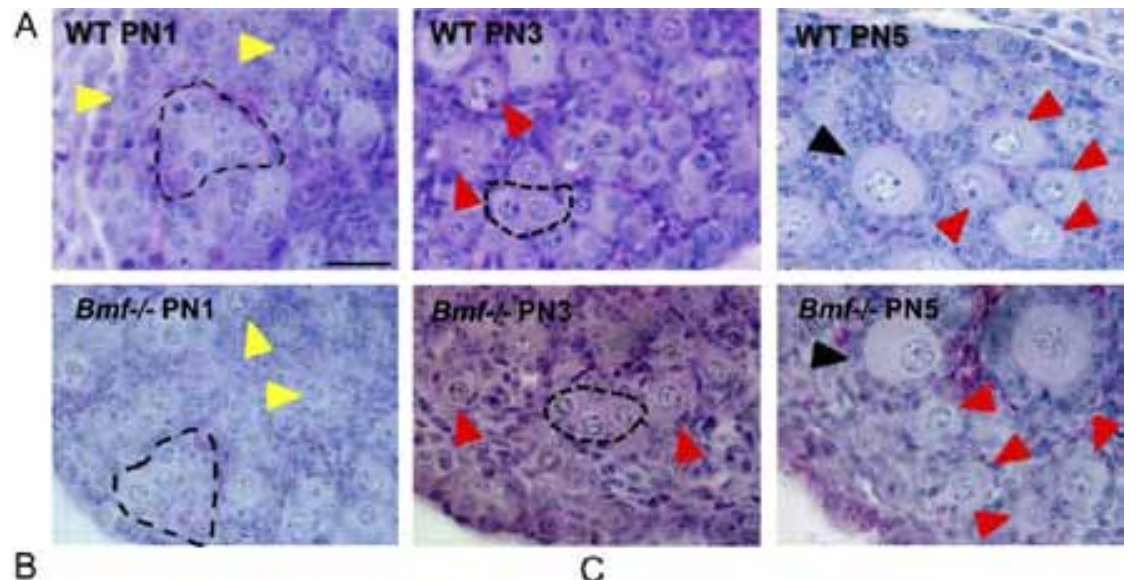

B
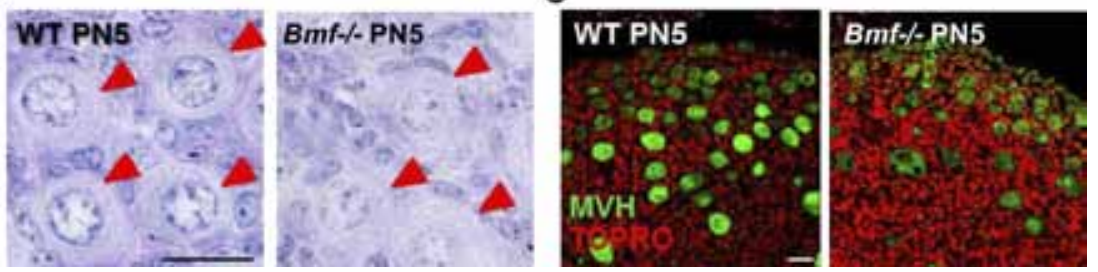

Figure 6 Nest breakdown and primordial follicle assembly in ovaries of WT and Bmf ${ }^{-1-}$ mice at PN1, PN3 and PN5. (A) Sections (20 $\mu$ m) stained with periodic acid-Schiff (pink) and counterstained with haematoxylin (blue/purple). Nest breakdown (PN1) is indicated by the presence of clusters of germ cells (dotted lines) and individual oocytes (yellow arrowheads). At PN3, small groups of oocytes (dotted lines) and more individual oocytes and primordial follicles (red arrowheads) were observed. Nest breakdown and follicle formation were complete by PN5, indicated by the appearance of individual primordial follicles (red arrowheads) and absence of nests and naked oocytes. Primary follicles were also evident (black arrowheads). Note: thickness of the sections makes images less clear. Scale bar, $25 \mu \mathrm{m}$. (B) Higher magnification showing primordial follicles. Scale bar, $15 \mu \mathrm{m}$. (C) Individual oocytes comprising primordial follicles could clearly be observed in ovarian tissue sections stained for MVH (green) and DNA (TOPRO3, red) at PN5. Scale bar, $25 \mu \mathrm{m}$. 
$B m f^{-1}$ ovaries, respectively, $\left.P=0.76\right)$. Nest breakdown was complete by PN5 in WT and $B m f^{-/-}$ovaries, as indicated by the formation of individual follicle-enclosed oocytes and the absence of clusters of naked oocytes (Fig. 6A, B and C). These observations indicate that BMF is dispensable for nest breakdown as well as primordial follicle assembly.

\section{Discussion}

More than two-thirds of the germ cells generated during oogenesis are eliminated, probably through apoptosis, before and during the time of primordial follicle formation. Precise regulation of this process is essential for ensuring that sufficient numbers of healthy oocytes are retained in the ovary to support female fertility and reproductive health, whereas low quality or damaged oocytes are removed. Despite the significant impact of germ cell apoptosis within the developing ovary, the mechanisms that control germ cell loss have not been fully elucidated. In this study, we investigated the role of the pro-apoptotic $\mathrm{BH} 3$-only protein, $\mathrm{BMF}$, in mediating germ cell death during ovarian development. We showed in mice that BMF is expressed in germ cells at E15.5, E17.5 and PN1 and that loss of BMF is associated with a reduction in apoptosis at E15.5 and E17.5 and an increase in germ cell numbers at E15.5 and PN1 compared with WT females. Importantly, loss of BMF resulted in a $\sim 36 \%$ increase in the peak germ cell number in $B \mathrm{mf}^{-1-}$ females compared with WT females. This suggests that under normal circumstances, BMF plays a prominent role in limiting the maximal number of germ cells achieved by the female.

The data suggest that the increased number of germ cells present in ovaries from $\mathrm{Bmf}^{-/-}$mice at E15.5 is most likely due to reduced germ cell loss between E13.5 and E15.5, which is consistent with the BMF expression profile and reduced number of TUNEL-positive cells in ovaries from $\mathrm{Bmf}^{-1-}$ mice. The increased number of germ cells observed in ovaries from $\mathrm{Bmf}^{-/-}$mice at E15.5 is unlikely to be attributed to increased proliferative activity or increased length of the proliferative period because our data show that a similar proportion of germ cells are proliferative at E13.5 and that proliferation had ceased and meiosis commenced at E15.5 in ovaries from both $\mathrm{Bmf}^{-/-}$and WT mice.

The increased number of germ cells in $\mathrm{Bmf}^{-/-}$ovaries at PN1 appears to be the result of a delay in germ cell loss caused by the prevention of BMF-dependent apoptosis. In ovaries from WT mice, approximately one-third of germ cells were lost from the ovary between E17.5 and PN1. In contrast, germ cell numbers remained unchanged in $\mathrm{Bmf}^{-1-}$ ovaries at E17.5 and PN1, with germ cell depletion beginning after PN1. The subsequent rate of depletion appeared to be accelerated, as the numbers of germ cells in ovaries from $\mathrm{Bmf}^{-/-}$females after PN1 were similar to the numbers seen in WT females at PN3, PN5 and PN10.

Our stereological data indicate that BMF is dispensable for the elimination of germ cells that occurs between E15.5 and E17.5, and after PN1. Indeed, TUNEL-positive cells were observed in $\mathrm{Bmf}^{-1-}$ ovaries at E13.5, E15.5 and E17.7, albeit at reduced frequency compared with WT ovaries. This demonstrates that BMF-independent mechanisms of cell death must operate in the ovary during this developmental stage. This finding may be due to functional overlap between several $\mathrm{BH} 3$-only proteins, such as BIM (Labi et al. 2008). Additionally, functional compensation for BMF by other BH3-only proteins may explain why the overall numbers of primordial follicles ultimately established in the ovary of $\mathrm{Bmf}^{-1-}$ mice at PN5 was similar to that in the WT animals, despite early increases in germ cell numbers.

Even though germ cell numbers fell after PN1 in $B \mathrm{ff}^{-/-}$mice, few TUNEL-positive cells were observed during this time in either WT or $\mathrm{Bmf}^{-1-}$ ovaries. The failure to detect large numbers of TUNEL-positive cells, or cells positive for other apoptotic markers, during known periods of oocyte loss is a phenomenon previously reported by us and others (Tingen et al. 2009, Myers et al. 2014). It is possible that apoptotic cells are eliminated from the ovary very quickly, such that detection of apoptosis in histological sections at individual time points is challenging. It has been reported that apoptotic elimination of even large numbers of rat liver cells only takes a few hours (Bursch et al. 1990). In experiments in which $\sim 25 \%$ of liver cells are eliminated per day, only $2-3 \%$ of the total cell population were found to be morphologically apoptotic at any one point in time (Bursch et al. 1990). Therefore, it is likely that we are only able to detect a fraction of the apoptotic cells in the ovary and this fraction may be too small to identify any differences in the numbers of TUNEL-positive cells between $\mathrm{Bmf}^{-/-}$ and WT ovaries at postnatal ages. Another possibility is that oocytes are eliminated through non-classical mechanisms of cell death (Tingen et al. 2009). In this regard, it has been suggested that germ cells can be eliminated from mouse ovaries by autophagy (Rodrigues et al. 2009).

BMF expression was detected in large numbers of germ cells at E15.5, E17.5 and PN1. The presence of BMF in germ cells during periods of germ cell loss supports a direct role for BMF in mediating their death. It is worth noting, however, that BMF can be negatively regulated at the protein level by sequestration to the cell cytoskeleton and release from the cytoskeleton is required for the induction of apoptosis (Puthalakath et al. 2001). Thus, it is not given that the numbers of BMF expressing germ cells, or even the levels of staining intensity, should precisely correlate with the numbers of germ cells lost during ovarian development as determined by stereology. We also detected BMF protein in somatic cells, most evident at E15.5. Therefore, while 
BMF is likely to be directly involved in germ cell death, there is a possibility that the increased numbers of germ cells in ovaries from $\mathrm{Bmf}^{-/-}$mice may also involve indirect effects mediated by improved somatic cell survival. Future studies using mice with BMF specifically deleted in germ cell or somatic cell populations would help to establish what proportion of germ cell loss, if any, is mediated indirectly through improved survival of somatic cells.

Collectively, these data suggest that BMF controls germ cell number at two time points during ovarian development: i) during early stages of the meiotic prophase (between E13.5 and E15.5) and ii) coinciding with the initiation of nest break down and meiotic arrest (between E17.5 and PN1), although apoptosis is not required for the nest breakdown process itself (Lei \& Spradling 2013). Although the absence of BMF resulted in elevated germ cell numbers at E15.5 and PN1, the numbers of primordial follicles established in the initial ovarian reserve were unchanged due to accelerated germ cell loss after PN1. These observations are reminiscent of those reported for $\mathrm{Bax}^{-/-}$mice (Alton \& Taketo 2007). Approximately 1.5 times more GCNA1-positive germ cells were observed at E14.5 and E18.5 in ovaries from $\mathrm{Bax}^{-/}$mice compared with ovaries from WT mice, suggesting that BAX plays an important role in the elimination of germ cells during the early stages of meiotic prophase (Alton \& Taketo 2007). However, germ cells were lost rapidly after this point and there was no significant difference in the total number of $\mathrm{MVH}$-labelled germ cells in ovaries from $\mathrm{Bax}^{-/-}$and WT mice by PN4PN5, leading to the conclusion that neonatal germ cell loss in mice does not require BAX (Alton \& Taketo 2007).

The meiotic prophase has previously been identified as a period of significant germ cell loss and it has been proposed that oocytes with meiotic errors are eliminated by apoptosis during this time (Borum 1961, Dietrich \& Mulder 1983, McClellan et al. 2003, Ene et al. 2013). This hypothesis is supported by studies showing that in mice lacking proteins required to complete meiotic recombination and DNA repair, such as ATM, DMC1, Trip13 and Msh5, oocytes undergo apoptosis before diplotene arrest (Barlow et al. 1998, Pittman et al. 1998, Li \& Schimenti 2007, Ene et al. 2013). Our studies suggest that BMF is also involved in the elimination of germ cells during the early stages of meiosis; whether or not this involves the elimination of germ cells with meiotic defects is not known.

The suite of physiological reasons underlying the death of germ cells remains unknown. In this study, we have demonstrated a key role for BMF in regulating germ cell apoptosis during both the early and latter stages of the meiotic prophase. Additionally, our findings show that germ cell death before E13.5 and after PN1 both occur independently of BMF. We have previously shown that PUMA mediates germ cell loss before the transition to meiosis, and thus likely has roles during ovarian development that are distinct from BMF (Myers et al. 2014). It is therefore plausible that different BH3-only proteins are responsible for eliminating germ cells for different reasons (e.g. unwanted or excess cells vs cells with DNA damage) at different times during ovarian development. Although the intrinsic apoptosis pathway is emerging as a central mediator of developmentally regulated germ cell death, much work needs to be done in order to completely understand when, why and how germ cells are eliminated from the ovary. Future analyses of mice lacking two, three or more $\mathrm{BH} 3$-only proteins are expected to provide interesting insight.

\section{Declaration of interest}

The authors declare that there is no conflict of interest that could be perceived as prejudicing the impartiality of the research reported.

\section{Funding}

This work was supported by fellowships and grants from the National Health and Medical Research Council (NHMRC Australia; project grant, K J Hutt (no. 1007027), C L Scott (no. 1062702); program grant nos 494802 and 257502; fellowships, J K Findlay (no. 441101), KJ Hutt (no. 1050130), C L Scott (no. 406675), P Bouillet (no. 1042629), A Strasser (no. 461299)), the Cancer Council Victoria (Sir Edward Dunlop Fellowship in Cancer Research, C L Scott), and the Victorian Cancer Agency (clinical fellowship, C L Scott). This work was made possible through the Australian Cancer Research Foundation, the Victorian State Government Operational Infrastructure Support and Australian Government NHMRC IRIISS.

\section{Acknowledgments}

The authors would like to thank Frank McKeon for his gift of the TAp63 antibody.

\section{References}

Alton M \& Taketo T 2007 Switch from BAX-dependent to BAX-independent germ cell loss during the development of fetal mouse ovaries. Journal of Cell Science 120 417-424. (doi:10.1242/jcs.03332)

Baker TG 1963 A quantitative and cytological study of germ cells in human ovaries. Proceedings of the Royal Society of London. Series B, Biological Sciences 158 417-433. (doi:10.1098/rspb.1963.0055)

Barlow C, Liyanage M, Moens PB, Tarsounas M, Nagashima K, Brown K, Rottinghaus S, Jackson SP, Tagle D, Ried T et al. 1998 Atm deficiency results in severe meiotic disruption as early as leptonema of prophase I. Development 125 4007-4017.

Borum K 1961 Oogenesis in the mouse. A study of the meiotic prophase. Experimental Cell Research 24 495-507. (doi:10.1016/00144827(61)90449-9)

Bursch W, Paffe S, Putz B, Barthel G \& Schulte-Hermann R 1990 Determination of the length of the histological stages of apoptosis in normal liver and in altered hepatic foci of rats. Carcinogenesis 11 847-853. (doi:10.1093/carcin/11.5.847)

Czabotar PE, Lessene G, Strasser A \& Adams JM 2014 Control of apoptosis by the BCL-2 protein family: implications for physiology and therapy. 
Nature Reviews. Molecular Cell Biology 15 49-63. (doi:10.1038/ nrm3722)

Dietrich AJ \& Mulder RJ 1983 A light- and electron microscopic analysis of meiotic prophase in female mice. Chromosoma 88 377-385. (doi:10.1007/BF00285860)

Ene AC, Park S, Edelmann W \& Taketo T 2013 Caspase 9 is constitutively activated in mouse oocytes and plays a key role in oocyte elimination during meiotic prophase progression. Developmental Biology 377 213223. (doi:10.1016/j.ydbio.2013.01.027)

Felici MD, Carlo AD, Pesce M, Iona S, Farrace MG \& Piacentini M 1999 $\mathrm{Bcl}-2$ and Bax regulation of apoptosis in germ cells during prenatal oogenesis in the mouse embryo. Cell Death and Differentiation 6 908-915. (doi:10.1038/sj.cdd.4400561)

Flaws JA, Hirshfield AN, Hewitt JA, Babus JK \& Furth PA 2001 Effect of bcl-2 on the primordial follicle endowment in the mouse ovary. Biology of Reproduction 64 1153-1159. (doi:10.1095/biolreprod64.4.1153)

Flaws JA, Marion SL, Miller KP, Christian PJ, Babus JK \& Hoyer PB 2006 Effect of bcl-2 overexpression in mice on ovotoxicity caused by 4-vinylcyclohexene. Toxicology and Applied Pharmacology 215 51-56. (doi:10.1016/j.taap.2006.03.003)

Ginsburg M, Snow MH \& McLaren A 1990 Primordial germ cells in the mouse embryo during gastrulation. Development 110 521-528.

Greenfeld CR, Pepling ME, Babus JK, Furth PA \& Flaws JA 2007a BAX regulates follicular endowment in mice. Reproduction 133 865-876. (doi:10.1530/REP-06-0270)

Greenfeld CR, Babus JK, Furth PA, Marion S, Hoyer PB \& Flaws JA 2007b $\mathrm{BAX}$ is involved in regulating follicular growth, but is dispensable for follicle atresia in adult mouse ovaries. Reproduction 133 107-116. (doi:10.1530/REP-06-0144)

Happo L, Strasser A \& Cory S 2012 BH3-only proteins in apoptosis at a glance. Journal of Cell Science 125 1081-1087. (doi:10.1242/ jcs.090514)

Hayashi K, de Sousa Lopes SM \& Surani MA 2007 Germ cell specification in mice. Science 316 394-396. (doi:10.1126/science.1137545)

Hunter N, Borner GV, Lichten M \& Kleckner N 2001 Gamma-H2AX illuminates meiosis. Nature Genetics 27 236-238. (doi:10.1038/85781)

Ke F, Bouillet P, Kaufmann T, Strasser A, Kerr J \& Voss AK 2013 Consequences of the combined loss of BOK and BAK or BOK and BAX. Cell Death \& Disease 4 e650. (doi:10.1038/cddis.2013.176)

Kerr JB, Duckett R, Myers M, Britt KL, Mladenovska T \& Findlay JK 2006 Quantification of healthy follicles in the neonatal and adult mouse ovary: evidence for maintenance of primordial follicle supply. Reproduction 132 95-109. (doi:10.1530/rep.1.01128)

Kerr JB, Hutt KJ, Michalak EM, Cook M, Vandenberg CJ, Liew SH, Bouillet P, Mills A, Scott CL, Findlay JK et al. 2012 DNA damageinduced primordial follicle oocyte apoptosis and loss of fertility require TAp63-mediated induction of Puma and Noxa. Molecular Cell 48 343352. (doi:10.1016/j.molcel.2012.08.017)

Labi V, Erlacher M, Kiessling S, Manzl C, Frenzel A, O'Reilly L, Strasser A \& Villunger A 2008 Loss of the BH3-only protein Bmf impairs B cell homeostasis and accelerates gamma irradiation-induced thymic lymphoma development. Journal of Experimental Medicine 205641 655. (doi:10.1084/jem.20071658)

Lawson KA \& Hage WJ 1994 Clonal analysis of the origin of primordial germ cells in the mouse. Ciba Foundation Symposium 182 68-84; (discussion 84-91).

Lei L \& Spradling AC 2013 Mouse primordial germ cells produce cysts that partially fragment prior to meiosis. Development 140 2075-2081. (doi:10.1242/dev.093864)

Li XC \& Schimenti JC 2007 Mouse pachytene checkpoint 2 (trip13) is required for completing meiotic recombination but not synapsis. PLoS Genetics 3 e130. (doi:10.1371/journal.pgen.0030130)

Liew SH, Vaithiyanathan K, Cook M, Bouillet P, Scott CL, Kerr JB, Strasser A, Findlay JK \& Hutt KJ 2014 Loss of the proapoptotic BH3-only protein BCL-2 modifying factor prolongs the fertile life span in female mice. Biology of Reproduction 90 77. (doi:10.1095/biolreprod.113.116947)

McClellan KA, Gosden R \& Taketo T 2003 Continuous loss of oocytes throughout meiotic prophase in the normal mouse ovary. Developmental Biology 258 334-348. (doi:10.1016/S0012-1606(03)00132-5)

Miles DC, van den Bergen JA, Sinclair AH \& Western PS 2010 Regulation of the female mouse germ cell cycle during entry into meiosis. Cell Cycle 9 408-418. (doi:10.4161/cc.9.2.10691)
Moldoveanu T, Follis AV, Kriwacki RW \& Green DR 2014 Many players in BCL-2 family affairs. Trends in Biochemical Sciences 39 101-111. (doi:10.1016/j.tibs.2013.12.006)

Mork L, Tang H, Batchvarov I \& Capel B 2012 Mouse germ cell clusters form by aggregation as well as clonal divisions. Mechanisms of Development 128 591-596. (doi:10.1016/j.mod.2011.12.005)

Myers M, Britt KL, Wreford NG, Ebling FJ \& Kerr JB 2004 Methods for quantifying follicular numbers within the mouse ovary. Reproduction 127 569-580. (doi:10.1530/rep.1.00095)

Myers M, Morgan FH, Liew SH, Zerafa N, Gamage TU, Sarraj M, Cook M, Kapic I, Sutherland A, Scott CL et al. 2014 PUMA regulates germ cell loss and primordial follicle endowment in mice. Reproduction 148 211-219. (doi:10.1530/REP-13-0666)

O'Donnell L, McLachlan RI, Wreford NG, de Kretser DM \& Robertson DM 1996 Testosterone withdrawal promotes stage-specific detachment of round spermatids from the rat seminiferous epithelium. Biology of Reproduction 55 895-901. (doi:10.1095/biolreprod55.4.895)

Pepling ME \& Spradling AC 2001 Mouse ovarian germ cell cysts undergo programmed breakdown to form primordial follicles. Developmental Biology 234 339-351. (doi:10.1006/dbio.2001.0269)

Perez GI, Jurisicova A, Wise L, Lipina T, Kanisek M, Bechard A, Takai Y, Hunt P, Roder J, Grynpas M et al. 2007 Absence of the proapoptotic Bax protein extends fertility and alleviates age-related health complications in female mice. Proceedings of the National Academy of Sciences of the United States of America 104 5229-5234. (doi:10.1073/ pnas.0608557104)

Pittman DL, Cobb J, Schimenti KJ, Wilson LA, Cooper DM, Brignull E, Handel MA \& Schimenti JC 1998 Meiotic prophase arrest with failure of chromosome synapsis in mice deficient for Dmc1, a germline-specific RecA homolog. Molecular Cell 1 697-705. (doi:10.1016/S10972765(00)80069-6)

Puthalakath H, Villunger A, O'Reilly LA, Beaumont JG, Coultas L, Cheney RE, Huang DC \& Strasser A 2001 Bmf: a proapoptotic BH3only protein regulated by interaction with the myosin $\mathrm{V}$ actin motor complex, activated by anoikis. Science 293 1829-1832. (doi:10.1126/ science.1062257)

Ratts VS, Flaws JA, Kolp R, Sorenson CM \& Tilly JL 1995 Ablation of bcl2 gene expression decreases the numbers of oocytes and primordial follicles established in the post-natal female mouse gonad. Endocrinology 136 3665-3668. (doi:10.1210/endo.136.8.7628407)

Richardson BE \& Lehmann R 2010 Mechanisms guiding primordial germ cell migration: strategies from different organisms. Nature Reviews. Molecular Cell Biology 11 37-49. (doi:10.1038/nrm2815)

Rodrigues P, Limback D, McGinnis LK, Plancha CE \& Albertini DF 2009 Multiple mechanisms of germ cell loss in the perinatal mouse ovary. Reproduction 137 709-720. (doi:10.1530/REP-08-0203)

Rucker EB III, Dierisseau P, Wagner KU, Garrett L, Wynshaw-Boris A, Flaws JA \& Hennighausen L 2000 Bcl-x and Bax regulate mouse primordial germ cell survival and apoptosis during embryogenesis. Molecular Endocrinology 14 1038-1052. (doi:10.1210/mend.14.7.0465)

Saitou M, Barton SC \& Surani MA 2002 A molecular programme for the specification of germ cell fate in mice. Nature 418 293-300. (doi:10.1038/nature00927)

Show MD, Folmer JS, Anway MD \& Zirkin BR 2004 Testicular expression and distribution of the rat bcl 2 modifying factor in response to reduced intratesticular testosterone. Biology of Reproduction 70 1153-1161. (doi:10.1095/biolreprod.103.023200)

Show MD, Hill CM, Anway MD, Wright WW \& Zirkin BR 2008 Phosphorylation of mitogen-activated protein kinase 8 (MAPK8) is associated with germ cell apoptosis and redistribution of the $\mathrm{BCl} 2$ modifying factor (BMF). Journal of Andrology 29 338-344. (doi:10.2164/ jandrol.107.003558)

Stallock J, Molyneaux K, Schaible K, Knudson CM \& Wylie C 2003 The pro-apoptotic gene Bax is required for the death of ectopic primordial germ cells during their migration in the mouse embryo. Development 130 6589-6597. (doi:10.1242/dev.00898)

Strasser A, O'Connor L \& Dixit VM 2000 Apoptosis signaling. Annual Review of Biochemistry 69 217-245. (doi:10.1146/annurev.biochem.69.1.217)

Stratton LG, Ewing LL \& Desjardins C 1973 Efficacy of testosterone-filled polydimethylsiloxane implants in maintaining plasma testosterone in rabbits. Journal of Reproduction and Fertility 35 235-244. (doi:10.1530/ jrf.0.0350235) 
Suh EK, Yang A, Kettenbach A, Bamberger C, Michaelis AH, Zhu Z, Elvin JA, Bronson RT, Crum CP \& McKeon F 2006 p63 protects the female germ line during meiotic arrest. Nature 444 624-628. (doi:10.1038/ nature05337)

Thomadaki H \& Scorilas A 2006 BCL2 family of apoptosis-related genes: functions and clinical implications in cancer. Critical Reviews in Clinical Laboratory Sciences 43 1-67. (doi:10.1080/10408360500295626)

Tingen CM, Bristol-Gould SK, Kiesewetter SE, Wellington JT, Shea L \& Woodruff TK 2009 Prepubertal primordial follicle loss in mice is not due to classical apoptotic pathways. Biology of Reproduction 81 16-25. (doi:10.1095/biolreprod.108.074898)

Villunger A, Scott C, Bouillet P \& Strasser A 2003 Essential role for the $\mathrm{BH} 3$-only protein Bim but redundant roles for $\mathrm{Bax}, \mathrm{Bcl}-2$, and $\mathrm{BCl}-\mathrm{w}$ in the control of granulocyte survival. Blood 101 2393-2400. (doi:10.1182/ blood-2002-07-2132)

Youle RJ \& Strasser A 2008 The BCL-2 protein family: opposing activities that mediate cell death. Nature Reviews. Molecular Cell Biology 9 47-59. (doi:10.1038/nrm2308)

Received 25 November 2015

First decision 22 December 2015

Revised manuscript received 22 February 2016

Accepted 25 February 2016 